\title{
Community Based Flood Risk Management: Local Knowledge and Actor's Involvement Approach from Lower Karnali River Basin of Nepal
}

\author{
Rabin Sharma \\ Samarpan Academy, Institute of Crisis Management Studies (ICMS), Tribhuvan University, Dhumbarahi, Nepal \\ Email: rabinsharma@tuicms.edu.np
}

How to cite this paper: Sharma, R. (2021). Community Based Flood Risk Management: Local Knowledge and Actor's Involvement Approach from Lower Karnali River Basin of Nepal. Journal of Geoscience and Environment Protection, 9, 35-65. https://doi.org/10.4236/gep.2021.96003

Received: May 10, 2021

Accepted: June 14, 2021

Published: June 17, 2021

Copyright $\odot 2021$ by author(s) and Scientific Research Publishing Inc. This work is licensed under the Creative Commons Attribution International License (CC BY 4.0).

http://creativecommons.org/licenses/by/4.0/

\begin{abstract}
Connecting to the disaster risk reduction (DRR) studies, community-based initiatives are found to be more effective in both developed and developing countries, with a specific focus on the empowerment of local communities to build resilience. Building on social capital theory, the paper investigates on local knowledge (LK) practices experienced by the actors in an emerging economy using the community-based flood risk management (CB-FRM) approach. The qualitative research method was used by collecting data from focused group discussions, and interviews with the key informants including actors from local governments and non-government organizations. Additionally, informal discussions, field visits, and desk studies were undertaken to support the findings. The findings reveal that the local communities carry out various local knowledge experiences to respond during disaster management phases. They own a creative set of approaches based on the LK and that empowers them to live in the flood-prone areas, accepting the paradigm shift from fighting with floods to living with that. The local actor's involvement is recognized as an essential component for CB-FRM activities. Yet, their program's implementation is more oriented towards humanitarian assistance in emergency responses. Even, they often overlook the role of LK. Additionally, the results show a high level of presence of local communities during the preparedness and recovery phases, while NGOs and local governments have a medium role in preparedness and low in recovery phase. The lack of local ownership has also emerged as the major challenge. The research provides valuable insights for integrated CB-FRM policies by adopting to LK practices.
\end{abstract}

\section{Keywords}

Community-Based Flood Risk Management, Local Knowledge, Social Capital 
Theory, Nepal

\section{Introduction}

The occurrence and robustness of natural hazards are significantly growing throughout the world; however, the balance of political, social, and economic environments can reduce the vulnerability to disasters (Shaw, 2012a). Increasing risks and impacts of hazards are threatening a sustainable impact on the economy and livelihoods of humans. Globally, 65 disasters are due to natural causes (IFRC, 2018). More than $90 \%$ of the disasters are originated from the main four types of hazards, i.e., floods, tropical cyclones, earthquakes, and droughts (Atta-ur-Rahman \& Khan, 2011). Of all these hazards, floods have been proved to be the most frequent one. Over 1.4 million people are affected due to floods and the estimated losses are equal to five billion US dollars damages to the infrastructure (UNDP/BCPR, 2018). The evidence estimates that there will be almost 325 million extremely poor people by 2030 (less than $\$ 1.25$ per day) living in locations that are most vulnerable to natural hazards (UNDRR, 2019). Overall, an average of 23.9 million people were displaced annually due to natural hazards from 2008 to 2018 (IFRC, 2018).

Whether disasters are large or small in scales, there are affected populations and local communicates who suffer the most. The local communities including volunteers are the first responder for any disasters (Kanta Kafle, 2018). However, extreme events are increasing people's vulnerability, particularly in the poorest communities. Such vulnerabilities could be exacerbated by the lack of preparedness and continuity of involvement of key actors in recovery and development stances. Largely, it could be due to a reason that the disaster management approach was mostly reactive and relief-driven (Shaw \& Krishnamurthy, 2009). Thus, disasters have been highly inflicted on the communities' people. However, the top-down approach has still been widely mostly implemented. Thus, the role of local communities and their engagement had been ignored to some extent. Since 90's, the concept of community-based disaster risk management (CB-DRM) has been globally accepted by communities as it most likely follows the people-centric (bottom-up) approach among the developing nations (Trogrlić et al., 2019; Tanwattana, 2018).

Under the umbrella of the CB-DRM approach, several sub-approaches are emerging to build community resilience towards different hazard risks. CB-FRM is one of those approaches under the shed of CB-DRM (Shiwaku \& Shaw, 2008). In many developed countries, traditionally, there are practical CB-FRM systems and activities in place from the $17^{\text {th }}$ century (Shaw, 2006). For example, practices in Japan and England are in different communities to manage the flood and other natural hazards (Shaw, 2012a). Additionally, they are applying bottom-up approaches to make disaster management more effective.

Developing nations such as Bangladesh and Vietnam have experienced ap- 
plying on CB-FRM, while governments have played a leadership role using top-down approaches instead (NPC Report, 2017). It means they have been living in the flood-prone area without adequately applying local knowledge practices experienced by their local communities (Shaw, 2012a). Although, such local communities might gain a collective and effective chain of practices essential to overcome or to manage disasters, their essential role has been undermined. Therefore, the exposure and proximity to hazardous events are continuously grown among such nations. It is well-understood that the local people respond to such as hazards earlier far before the arrival of delivery of assistance by humanitarian organizations at times of crisis and the affected population can more quickly deal with the situations rather than other actors (Portes, 2000).

This study connects to the CB-DRM and CB-FRM approach to fill the gap on interaction among the engaged actors in the event of a disaster. More specifically, the paper investigates on LK practices experienced and the actors including local communities, the local government, and non-government organizations in the CB-FRM.

Further, the study site for this research is one of the most flood-prone communities in western Terai surrounded by two bigger rivers (Karnali and Garuwo) branches of Karnali. In 2017, the monsoon flood massively affected all Terai parts of Nepal (NPC Report, 2017). The study area was in $4^{\text {th }}$ rank in terms of damages and loss of life out of 32 districts. The results provide insight to the policy makers at humanitarian organizations and the local government when they plan to prepare for, response to or recovery from the disasters.

Overall, this paper seeks to address the following research objectives:

- To explore the actor's involvement in community-based flood risk management (CB-FRM)

- To explore the practices experienced based on local knowledge (LK).

The remainder of the current paper is organized as follows. In Section 2, we provide an overview of the conceptual background of the study connecting to the both theory and practice. In Section 3, we describe of the case study as a method used for the research. In Section 4, we describe major results based on the research questions. In Section 5, the conclusion of the results, connecting them back to the previous literature, is provided, and we present several implications for research and practice together with limitations.

\section{Conceptual Background}

\subsection{Social Capital Theory and Disaster Risk Management}

The Social Capital Theory (SCT) is defined that social relationships are resources that can lead to the development and accumulation of human capital. One systematic way of looking at communities of knowledge is by using the social capital theory (Miller, 2001). This is prominent in several contexts (Leonard \& Onyx, 2004). However, here in the study, the SCT prime theme is to determine the relationships between people to people and people to actors, both in pre-disaster 
(e.g., preparedness) and post-disaster (e.g., recovery) phases.

It provides insight into how community people can take into account building local capacities (Nakagawa \& Shaw, 2004) by making reciprocities with one another and having them going over time. People can work mutually to deliver things they either could not achieve by themselves or could only achieve with high complexity (Meyer, 2018). People attach through a series of networks and they perform to share common values with other members of their networks to generate strong DRM activities (Minamoto, 2010); to the extent that these networks develop a resource. They may be seen as creating a kind of bonding, bridging, and linking which are the three-dimensions of SCT (Minamoto, 2010). Bonding associates with the connections between people with similar characteristics and tends to reinforce homogeneity and inclusiveness. Bridging talks about the connection between people from one community to another to share their ideas and values. Linking is related to relationships between community peoples and different actors who are present in the community to provide resources, and the required local data and information.

In the context of disaster studies, SCT has been adopted to better and deep understand how local people at risk use the optimum level of local resources to meet the urgent needs of a disaster (Wannous \& Velasquez, 2017). In addition, it is a continuous relationship between staff and members which will, therefore, make the transfer of knowledge from the government staff to the community easier. It further helps to promote oneself to defeat the gap between actors and communities which eventually established the CB-DRM approach faster than other approaches (Parvin, Takahashi, \& Shaw, 2008). Therefore, the researchers have analyzed the community perception about their coordination, connection, developing a sense of belongingness, knowledge transfer, improved communication skills, creation of networks through the lens of three-dimension of SCT in the context of CB-FRM.

\subsection{Community-Based Disaster and Flood Risk Management}

The integrated community people have the same aim to reduce the community level hazards by themselves (Joerin, Shaw, Takeuchi, \& Krishnamurthy, 2012). UNISDR defines "CB-DRM is a process, which leads to a locally appropriate and locally "owned" strategy for disaster preparedness and risk reduction" (Iloka, 2016a). In the past 20 - 30 years, the need for CB-DRM is taking place into account (Dube \& Munsaka, 2018). Because, in recent times, more research has been conducting in various fields that showed the approach to CB-DRM became more useful for effective management of natural hazards (Bosher \& Dainty, 2011). Moreover, it helps involved actors to identify and map the local capacities to cope with disasters through LK on Disaster Risk Reduction (DRR). A myriad of outcome can be obtained using CB-DRM approach, not limited to, but include helping local needs, improving planning and implementation, strengthening project performance and acceptance, contributing to sustainability and cost-effectiveness, creating trust, ownership, and increased self-resilience in 
communities (Lewis, 2012). The approach helps policy makers at local level to administer adequate disaster preparedness through the utilization of community resources (Laursen, 2015).

Furthermore, DRR has two main approaches which are namely traditional and professional (Adhikari \& Sitoula, 2018). The traditional approach of risk reduction was very popular in 1980s and 1990s, which seems gradually evolved into the CB-DRM, and then later, it changed into community-based disaster risk reduction (CB-DRR) (Izum \& Shaw, 2012). CB-DRM and CB-DRR are often used with similar meanings, with the concept of an enhanced focus on "risk" (Shiwaku \& Shaw, 2008). However, there is still a thin line of distinction. According to (Shaw, 2012a), CB-DRR focuses more on pre-disaster activities for risk reduction by the involvement of communities, whereas CB-DRM focuses on a broader perspective of risk-reduction-related activities by communities' people involved in before, during, and after the disaster (Jones, Oven, Manyena, \& Aryal, 2014). Thus, under the CB-DRM approach, CB-FRM comes into priorities which are considered as an important component to build the community resilient through the bottom-up approach (Bhattarai, 2018). For instance, in Japan local communities have been responding and managing disaster risk for centuries-long (Hollweck, 2016; Robert K. Yin., 2014). Before the creation of Japan's formal state system, local communities carried out disaster-related activities with their basic understanding, awareness, and indigenous knowledge as voluntary (Tuladhar, Yatabe, Dahal, \& Bhandary, 2015). They are working on the bottom-up approach with the central government (Gero et al., 2011). As a result, the community level disaster risk management is well formulated in Japan (Tanwattana, 2018).

\subsection{The Research Gap}

The developing countries such as Nepal, India, Vietnam, Bangladesh, and Pakistan, are practicing a top-down approach. But the implementation and monitoring are still weaker due to the communities are not well equipped and aware enough to face disasters as they are not involved directly (Smith, Brown, \& Dugar, 2017). There are several gaps in the management of disasters at the community level due to little awareness efforts, less practice of LK, and inadequate support from different levels of government and actors (Poudyal Chhetri, 2001).

More specifically, in the case of Nepal, the local government has a direct connection with the community people to establish proactive disaster management (Kanta Kafle, 2018). Yet, there has not been any clear note and/or discussion of recognizing and including the local community initiatives and clear guidelines to capitalize on these vital resources in the immediate aftermath of disasters as well as in normalcy to make a community resilient through robust disaster preparedness and recovery planning (Lee, 2016). It shows that effective flood risk management (FRM) in Nepal has yet to adopt. It is revealed that a huge research gap whilst establishing the concept of CB-FRM. Therefore, Nepal needs to ex- 
plore the concept of CB-FRM based on the local knowledge experienced by the involvement of the local actors during the disasters. It is based on immediate participatory and people-centric approaches, and establishing the foundation of DRR at the local level.

\section{Research Method}

This is a qualitative study and follows the case study research approach (Gautam \& Phaiju, 2013). The current paper has exclusively focused on the two phases of preparedness and recovery to explore on local knowledge practices experienced by local actors. It has been successfully used for an in-depth analysis of CB-FRM. To establish the research gap, we conducted a narrative literature review through national and international research journal papers. After reviewing the literature, the gap and practical research problem are identified and that led to explore the phenomena further using qualitative approach. Figure 1 illustrates the overall study design procedures. For the purpose of data collection, we rely on both secondary data (etc., annual reports on flood, climatology data published by the government) and primary data including interview, focused group discussion, key informant interview, and field observation.

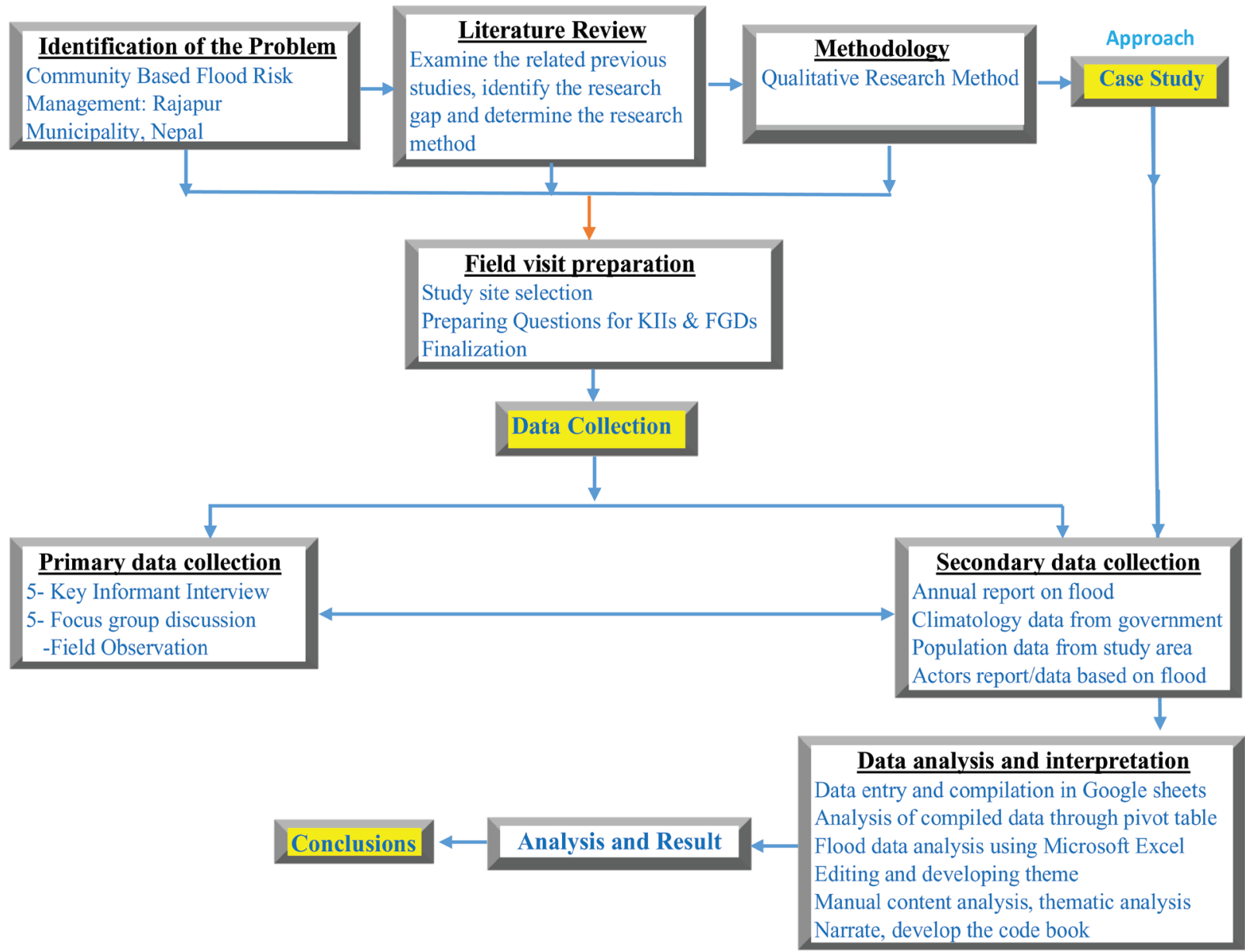

Figure 1. Research design of the study. 
Fieldwork was undertaken between the months of August to December 2020, a year after the extreme 2017 floods, and while the country was still experiencing the annual floods in 2018 and 2019 respectively. We had a set of studies conducted on both phases' preparedness and recovery. The data collection process was designed through primary and secondary sources. In the initial stage of data collection, we have identified the vulnerable communities' groups and beneficiaries of FRM related projects undertaken through NCCSP.

Thereafter, for the primary data, Focus Group Discussion (FGDs) were held with community groups, and Key Informant Interview (KIIs) with the potential actors' groups (presented in Table 1). The interview questions were designed and asked in the local language (i.e., Tharu and Nepali) to minimize the language barrier for the respondents. Further, all the respondents were primarily selected using a purposive sampling technique (i.e., selection of respondents directly applicable to the current research aims). The questions were designed to open and closed-ended form. It has covered five main themes, namely; flood local knowledge/practices, state of preparedness, state of recovery, and the role of actors' involvement in FRM. Finally, then, all the respondent answers were translated from (Tharu and Nepali) to English. All FGDs and KIIs were audio-recorded and note-taking then transcribed, coded, and analyzed using thematic analysis.

Following the main objectives of the research, the themes were created according to the local practices and actors' involvement in CB-FRM. While FGDs and KIIs were the primary data sources. Supplementary, other relevant information was gathered through informal discussion with the local aged people and through field visits related to their local knowledge to see the impact of the recent floods. All these supplementary data proved invaluable to create an accurate image of the reality of CB-FRM. The field observation and casual talks were recorded in a form of comprehensive note-taking.

Table 1. FGDs and KIIs participants a demographic overview.

\begin{tabular}{|c|c|c|c|c|c|c|c|c|}
\hline \multirow{2}{*}{ Village } & \multirow{2}{*}{ Groups } & \multicolumn{4}{|c|}{$\begin{array}{l}\text { Focus Group Discussions } \\
\text { (FGDs) }\end{array}$} & \multicolumn{3}{|c|}{$\begin{array}{l}\text { Key Informant Interviews } \\
\text { (KIIs) }\end{array}$} \\
\hline & & Male & Female & Education & Occupation & Actors' & Male & Female \\
\hline $\begin{array}{c}\text { Tadiya } \\
\text { Chhakhapur }\end{array}$ & Project beneficiaries' peoples & 5 & 4 & & & $\begin{array}{l}\text { Local } \\
\text { development officer }\end{array}$ & 1 & - \\
\hline $\begin{array}{l}\text { Tighar } \\
\text { Nagapur }\end{array}$ & Flood experienced peoples & 6 & 6 & Primary (44\%) & Agriculture (53\%) & Ward chairperson & 1 & - \\
\hline $\begin{array}{l}\text { Sidharwo } \\
\text { Parayakpur }\end{array}$ & Youth members & 7 & 7 & Secondary (34\%) & $\begin{array}{l}\text { Student }(23 \%) \\
\text { Government Job (16\%) }\end{array}$ & Deputy mayor & - & 1 \\
\hline $\begin{array}{l}\text { Muriya } \\
\text { Basanta }\end{array}$ & CBDM members & 4 & 8 & Higher $(22 \%)$ & Private Job (8\%) & $\mathrm{I} / \mathrm{NGO}$ & 1 & - \\
\hline Rajapuruwo & Vulnerable peoples & 5 & 7 & & & Red Cross & - & 1 \\
\hline 9 Villages & 5 FGDs group & 27 & 32 & & & 5 KIIs & 3 & 2 \\
\hline
\end{tabular}


Similarly, the secondary data were collected from local government and I/NGO offices to analyze potential flood risks to human life, infrastructures, and settlements in the Karnali river bank. The identified potential flood hazard areas were plotted in the GIS-based structured layout map. The plots were then digitized through ArcGIS (10.6) version. Flood prone areas and bank cutting areas were plotted and digitized in the hazard map shown in Figure 2.

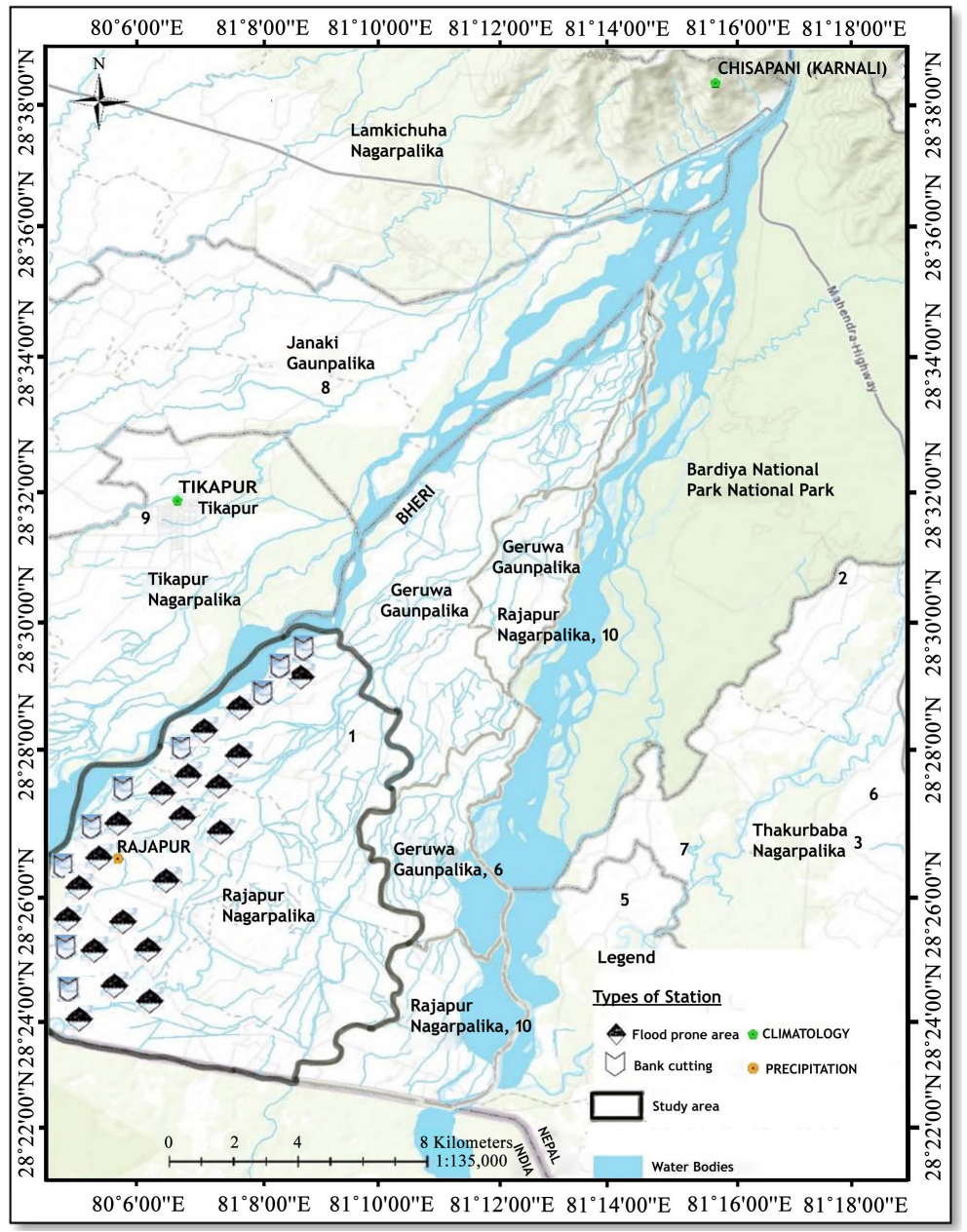

Figure 2. Digitized hazard map of Rajapur Municipality.

\section{Study Area}

The fieldwork was conducted in Rajapur Municipality of Bardiya district. It lies in Lumbini province. It has covered 2025 square Kilometers. Most of Bardiya is considered infertile Terai plains, covered with agricultural land and forests. The northernmost part of the district extends into the Churiya or Siwalik Hills. Rajapur is situated just beneath the Chisapani gorge where the Karnali River plunges Rajapur and is divided into two districts namely; Bardiya and Kailali. The banks of the river are unstable, change through seasonal inundation that plays a significant role in cutting the lands of Rajapur. The study area has shown in Figure 3. 


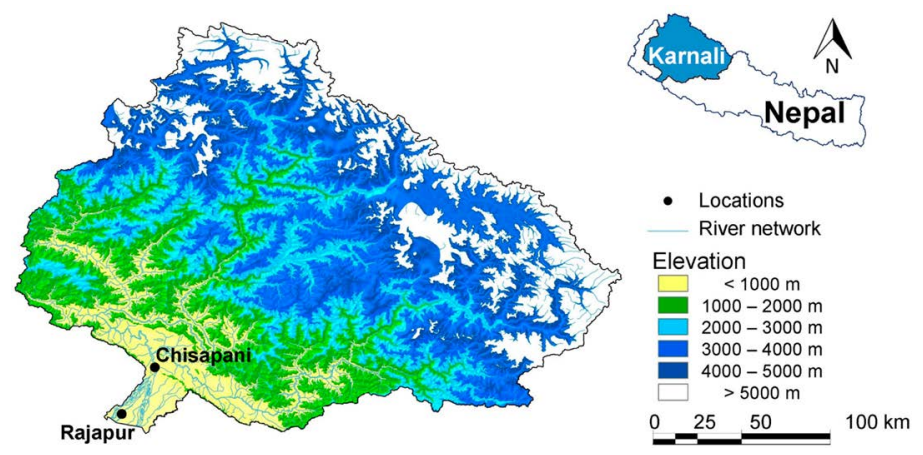

Figure 3. Map of the study area as included both Karnali River and Geruwo River which is lying in the Nepal-India border.

In the study areas, there were altogether nine villages. It lies approximately 55 $\mathrm{km}$ west (Gulariya-Rajapur postal highway) from the Gulariya municipality. Bardiya district itself represents different diverse socioeconomic statuses, various ethnicities, and geographical settings. According to the census data from 2011, the total household count is 1005 with a total population of 5834 where 2823 male numbers and 3011 females. The diverse communities of people are living where almost $80 \%$ belong to the Tharu indigenous community. Furthermore, Rajapur municipality is considered a pioneer in implementing the Local Adaptation Plans of Action (LAPA), National Adaptation Programs of Action (NAPA), Community Adaptation Plans of Action (CAPA), and Nepal Climate Change Support Program (NCCSP) and many other food-related projects. The programs were carried out by various actors. The areas were selected as it has been considered one of the highly flood-prone areas, and experiencing significant flooding on an almost annual basis, and most vulnerable and marginalized communities reside there. Thus, assessing the CB-FRM practices in the area can be useful to redesign the entire plans and policies on disaster management strategies to overcome flood risks.

\section{The Case Selection}

In the case of Nepal, the level of poverty allied to a lack of access to proper land and employment, often drive people to settle in zones highly exposed and vulnerable to natural hazards (Bajracharya, Shrestha, \& Shrestha, 2017). In the last 50 years (1970-2019), a total of 4631 flood events were reported where, with 4058 deaths, 45,166,887 affected families, and 178,833 families were displaced (Ministry of Home Affairs, MoHA/DRR Portal, 2019). Nepal ranks $30^{\text {th }}$ in terms of risk and vulnerability to floods (Ministry of Home Affairs, MoHA/DRR Portal, 2019). In a country where $80 \%$ of the population economy is overwhelmingly agricultural-based. The annual flooding occurrences significantly impact livelihoods as they directly affect income generated from agriculture (Shaw \& Krishnamurthy, 2009). According to the Post Flood Recovery Report of 2017, the flood-affected around 1.7 million people, and it was hit $46 \%$ of areas of Nepal (NPC Report, 2017). It destroyed 41,626 houses and partially destroyed 
150,000 houses (NPC Report, 2017). The estimated value of the damage is NPR 60.71 billion, which is equivalent to $3 \%$ of the total GDP of Nepal (NPC Report, 2017).

The government of Nepal has prioritized the improvement of flood resilience of communities and infrastructure through the various programs but yet to address the ground reality of the community with appropriate management action towards the effective preparedness and recovery of the flood's disaster (Shaw \& Krishnamurthy, 2009). Nepal has the National Disaster Risk Reduction and Management Act (NDRRMA), which has been updated in 2017, as a new act with the function of six-layers of government system from the federal to the local level (i.e., top-down approach).

NDRRMA, 2017 is recently formulated in Nepal which replaced the Natural Calamity Act (NCA) 1982. The need for a proactive disaster management act in Nepal was desired since the early 90 s to cover the whole gambit of disaster management (Shaw \& Krishnamurthy, 2009). It also clearly outlines the functions and duties to disaster management of the federal, provincial, and the local line with the community level. This new Act has adopted in line with Sendai Framework for Action (2015-2030) recognizing the need for risk reductions along with disaster management with an envisioning of six-layers of disaster management institutions (Pandey, 2019a). For its effective enforcement, the hierarchy of NDRRMA has been led by deferment government bodies from the central to a local level (as presented in Figure 4) and Study of the framework has shown in Figure 5.

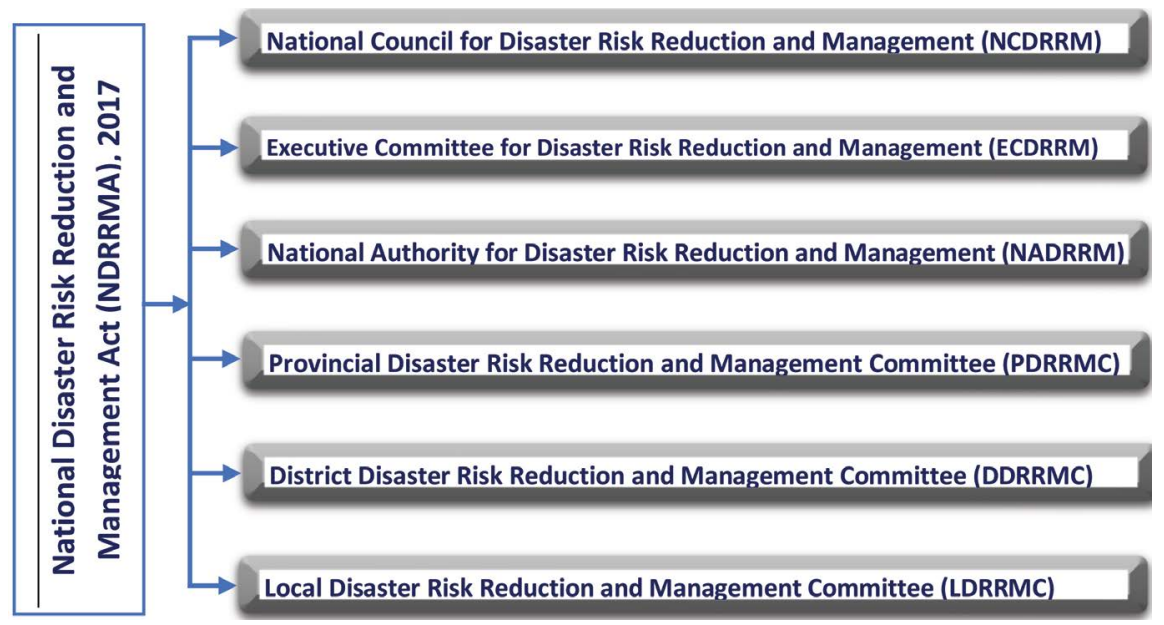

Figure 4. The six layers of NDRRMA act, 2017 (Adopted by (Pandey, 2019a)).

Similarly, the Disaster Risk Reduction National Strategic Action Plan (2018-2030) line with NDRRMA, 2017 has been endorsed upon the chairmanship of the Prime Ministry. This policy has been in line with the recent global agenda including the Sendai Disaster Risk Declaration (2015-2030). The main thrust of the new legislation is to move forward from managing "Disaster" to managing "Risk" (Nepal, Khanal, \& Pangali Sharma, 2018). These steps are a 
major departure from the "Reactive" to the "Proactive" approach from the central level to the local community level (Ahmad \& Zahir Ahmed, 2019). After these plans, policies, and strategies the federal government will be implemented. It is said that a Single-Door Policy will adopt in the disaster management cycle (Lee, 2016). Even roles and responsibilities have been distributed from the central to the local level of government with the top-down approach. Nonetheless, there is still a gap for clear recognition of community participation and initiatives. Likewise, the government is more focused on relief rather than preparedness and recovery (Lee, 2016). Meanwhile, undecided guidelines to utilize the LK and local resources lead to ineffectiveness in disaster management (Bajracharya, Shrestha, \& Shrestha, 2017).

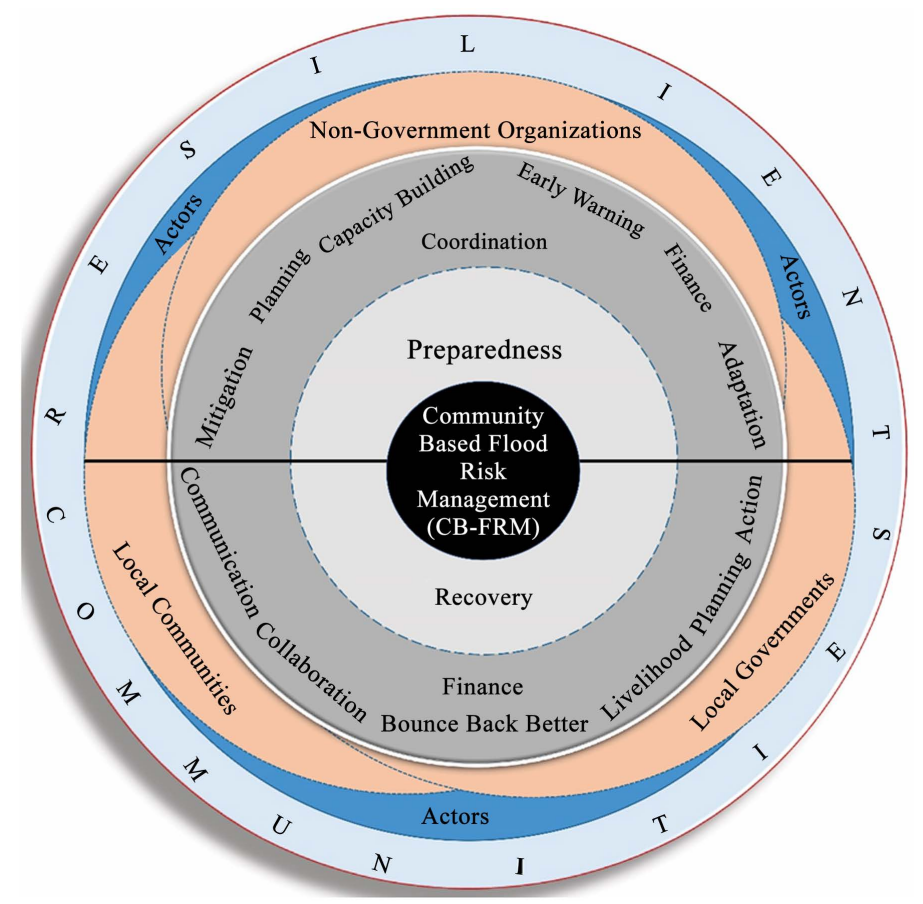

Figure 5. Conceptual framework of the study.

\section{Results}

The section deals with the main findings obtained from the field study. The main findings are:

\subsection{Actor's Involvement in CB-FRM}

The empirical findings of the study potentially indicate that various actors were present across different phases of the CB-FRM. Local actors are categorized in three groups of non-government organizations, local governments, and local communities. It is very hard to achieve an effective CB-FRM without the involvement of various actors. Especially the local communities are the first responders for any disaster. However, the community is not sufficient and able to deal with the complex process where actors play a crucial role through operation 
involving resources beyond the local capacity. Building on SCT, this study goes deeper to identify how actors engaged throughout the CB-FRM cycle based on three-dimensions of bonding, bridging, and linking. At the same time, actors should involve to design and implement primarily with the local community, regional, and national government, which helps towards effective and timely management of activities. Within this context, the identified views detailed below are described from each of actors' perspective. Furthermore, the overview of the general findings of actors' involvement is summarized in Table 2.

Table 2. Overview of the findings of actors' involvement.

\begin{tabular}{|c|c|c|}
\hline \multirow{2}{*}{ Actors } & \multicolumn{2}{|c|}{ Activities Involvement in Phases } \\
\hline & Preparedness & Recovery \\
\hline Local Government & $\begin{array}{l}\text { - Coordination of all DRR activities at the community level } \\
\text { through NGOs } \\
\text { - } \quad \text { Preparing the DRR plans } \\
\text { - } \quad \text { DRR education } \\
\text { - } \quad \text { Mobilizing of resources for training } \\
\text { - } \quad \text { Identification of potential disaster prone-areas }\end{array}$ & $\begin{array}{ll}\text { - } & \text { Financial support } \\
\text { - } & \text { Logistic support } \\
\text { - } & \text { Support to build the damaged shelters }\end{array}$ \\
\hline Local Communities & $\begin{array}{l}\text { - } \quad \text { Participating in DRR training (e.g., flood-early warning) } \\
\text { - } \quad \text { tilizing local resources and knowledge for dam } \\
\text { - } \quad \text { Building the two-storey houses } \\
\text { - } \quad \text { Storing the food for emergency purpose } \\
\text { - } \quad \text { Establish the village disaster management fund } \\
\text { - } \quad \text { Election the village messenger (Chowkidar) for } \\
\text { information dissemination }\end{array}$ & 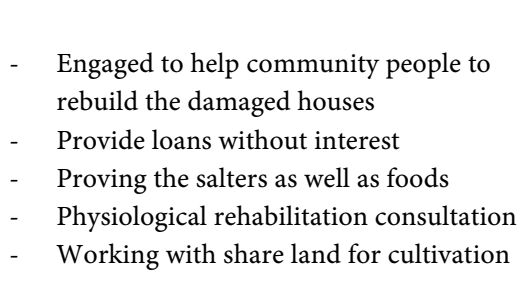 \\
\hline
\end{tabular}

\section{Non-government organizations}

During the investigation, many non-government organizations (NGOs) were present in the study area. It is found that their primary roles are developing DRR plans as well as identifying potential local hazards and vulnerable communities' people to support the community. These activities are the working basis of the vertical approach with coordination of local government and community leaders. In their DRR plan, they focused basically on; community-based early-warning system, capacity-building activities, drills, and training, promotion and support for the community-saving concept, social awareness campaigning, construction of safe shelters. It shows that actors' participatory process has been recognized as an essential element for CB-FRM, which builds on a culture of safety and ensures sustainable development as well as capacity development of the community. However, there were gap in terms of learning and sharing to 
enhance the accountability of the communities. But this can be done through the sharing of experiences, peer-to-peer learning, local knowledge transfer as well as bringing together community members by rotating host communities for ongoing discussions, sharing of issues, and celebration of achievements that help to promote capacity-building. It shows that the local knowledge transfer, experiences, and local resource utilization are overlooked in their plan.

In terms of the preparedness phase, NGOs always had to present their role as creators and advisors. Preparedness reduces and limits the destructive and disruptive effects of hazards on the elements at risk (Pandey, 2019a). In the study, NGO participants also highlighted that they are implemented their preparedness work plan through structural and non-structural measures. In the structural measures, such as engineering works like protective dikes, embankments, safe building design, high raised houses and taps water, early waning installation at the community level, culverts management, and gabion wall. Further, to the non-structural measure such as community risk awareness, community DRR planning, public awareness, flood security programs, crop insurance, strengthening community disaster management committee, established the community disaster saving found group, identify the open spaces, and evacuation route.

Further, the actor's group mentioned that, due to the unusual behaviors of some NGOs, they start to work within the same villages where already projects were running, which lead duplication in the work and community people are getting confused and later it is an impact to the participation of the community people in essential preparedness activities. On the contrary, another statement came from (NGO member, Rajapur), "perhaps community peoples taking participation low in preparedness activities such as drills and training might be years of gap in flooding's, they can be assumed that flood will not be coming this year as well because in the past we don't have flood events". So, it could lead to the wrong direction in terms of preparedness measures. Despite all challenges, community-based projects have also formed a youth forum in each village and provided education on flood preparedness activities. Apart from training and capacity building, NGOs project also were focused on livelihood activities such as alternative farming agriculture in the recovery process. Though NGOs were worked in the communities but their activities were more towards relief rather than preparedness and recovery that is the gap in the study area.

The challenges were pointed out (NGO member, Nagapur) as; "while engaging during the recovery process, some communities have their way of the living standard with their cultural value. But we have the same designed plan for all and they don't accept our concept of recovery activities (e.g., construction of new houses with modification or transfer them into different places. They just take some relief material to survive and ask for cash but we don't allow such facilities. However, it is based on the plan so, sometimes we support them through cash as well'.

Recovery is the decision and action taken after a flood event to restore or improve the post-disaster living conditions of the stricken community (Allen, 
2006). Communities are taking 3 to 5 months' duration to re-establish and back to normal conditions again. In the phase of recovery and rehabilitation the process involves more than just fixing up the physical items. The local community shows that they need psychosocial support to restore their normal life after the incidents. In the statement (NGO member) said that they are already heard such hidden problems from the community. Therefore, they are running such restoration campaigns aftermath of the disaster to support them back to their normal life.

In some cases, traditionally dominant groups are controlling community institutions such as NGOs and other actors' group as their power reached up to the government level (Local NGO member, Rajapur). It influencing us in a negative direction, as the projects are directly connected with local government and local leaders. As a result, the continued marginalized of prohibited groups and potentially vulnerable groups are dominated during the recovery phase because recovery is always action-oriented and is directly and indirectly dependent on finances. Further, on this point, (Local NGO member, Tadiya) has given the same thought that "the projects have a limited recovery budget and couldn't entertain by providing every facility as projects bounded from the rule and program design".

Furthermore, the findings reveal that the actors have been engaged in a recovery activity such as immediate repair of damaged infrastructure, support to self-help housing rehabilitation, immediate income-generating activities, employment-intensive rehabilitation, and improvement of support service (e.g., rubble removal activities through a cash-for-work program). In this regard, NGO members emphasized that aftermaths of disasters, there are many activities related to reconstruction work and for that, we hire local community people for construction on the road, bridge, culverts, drainage channels construction as a cash-for-work approach.

\section{The Local Government}

The local government has an innate responsibility to ensure the safety of its community from disasters. The government leaders are expected to adequately take action on preparedness and recovery phases. Primarily, the local government is represented by the municipality and ward level government. Their role in disaster activities is mobilizing resources, provide facilities such as training, awareness, DRR education, engaging communities in DRR activities throughout the years. During the analysis process, we found that the local government is directly dependent on non-government organizations' projects. Further analysis revealed that they have developed DRR related plans. However, the governments are yet to be clarified by standard guidelines for effective implementation. Similarly, their role is to the identification of potential disaster prone-areas and takes an action, where flood hazard is the most frequent one. They considered this is one prominent issue in their locality. But it is purely overlooked to deliver the action. In particular, the sharing of information and responsibilities between the provincial and local levels has not been defined in detail (local government rep- 
resentatives, Rajapur municipality). There is no standard communication protocol between the chairs of federal, provincial, and local government committees. This may negatively affect coordination for effective disaster preparedness and recovery. Yet, they continuously direct NGOs' projects to impacts and needs assessment (municipality representative, Rajapur).

However, a stable federal system of governance, with the power developed to the local authorities (at Gaupalikas and Municipalities) and legally mandated from the government through the NDRRRM Act, 2017. The local government operation Act, (LGA) 2017, has guided the risk reduction processes with the involvement of local government. However, the result revealed that the local government only progress on the vertical approach with communities due to the lack of resources, technical manpower, and low budget (municipality representative, Rajapur). In the same issue raised by:

Ward, representative, Sidharwo, from the central government: the disaster activities budget allocated is very low, and when it comes to our boundary that is very minimal which couldn't hire skilled manpower and difficulties to facilitate communities and we always depend on NGOs founding for the preparedness and recovery activities.

The respondent further added that they have planned to develop WDMC guidelines for effective disaster management activities. Under the LGA functions, there are twelve specific authorities including making plans and police for disaster preparedness and recovery, mobilizing municipal police for rescue and relief, mapping of risk areas and relocation, coordination with the provincial and central government, non-government organizations, data management, and research among others. In the contrast, the local government official highlighted in the above functions, yes law is there but "our hands are tied, we don't have any real power, we have seen affected houses damaged by the floods but we have not been able to provide the cash or fully recovery guarantee". However, it doesn't mean we did nothing we carry several flood preparedness and recovery activities in terms of short (coping) and long (adoption) such as afforestation, planting trees, drought resistance crops, collecting fund for disaster management from the community, and ward level, muck drill, school teacher training, road dramas for awareness as a preparedness measure.

Nevertheless, local governments are involving local communities through the CB-EWS for training and drills. Despite that, there were challenges regarding adopting new technology, our community has a low literacy rate and more than $80 \%$ of the community belongs to the Tharu ethnicity. Still, they have using the Tharu language for communication. However, yet EW messages are delivered by the Nepali language which is needed to change or modified by the multi-language approaches. For that, local governments are frequently coordinating with NGO representatives and local authority persons (i.e., who is chosen in each village is called Chaukidar - Messenger). He is an effective and active person to disseminate EW messages in each HHs by mouth-to-mouth service. However, later, they were realized that disseminating the EW messages by 
mouth-to-mouth is taking a long time to deliver messages. Therefore, local governments provided a siren and megaphone for him, which is far better to replace mouth to mouth publicity.

Although recognized the important role that the local government plays in the CB-FRM, the participants have emphasized that several challenges related to the recovery activities. This comprised unusually support during the recovery processes that repeatedly leading towards duplication of the logistic support in some areas and a rarity of activities in others. According to participants, it is essential to follow the conventional system, precisely during the recovery and response phases. It is failed to do so often creates disorder at the community level. Respondents felt that there is a need for increased monitoring and accountability of local government and NGOs towards the transparency of distribution. The same point also has been seen from the literature review, local government, and NGOs' support for relief and recovery is highly influenced by discrimination characters. It was noticed that due to politics. Lastly, there needs to change in overall activities for the effectiveness and transparency of the existing system, through a better action plan and strong cooperation, coordination, and communication strategies between major actors (Local government, representative, Rajapur).

\section{Local Communities}

The local communities play a pivotal role in undertaking many kinds of activities in CB-FRM. It has contributed through various ways such as coordinating, facilitating individual efforts, building synergy effects, and reducing the cost of program operation. Likewise, strengthening solidarity effectiveness of cooperation within communities, providing a platform for consensus-building and conflict avoidance, thereby building local social capital. In the study area, there we found each community has community disaster management committee (CDMC) formed by the support from local representatives (i.e., ward chairperson and NGOs). These groups are very active in terms of flood risk management. Initially, this ad hoc committee was formed without considered diversify. Later, it is organized through involving different background people such as youth, aged, community leaders, teachers, women, common peoples, and other ethnic groups (CDMC member, Tadiya). Nevertheless, the committee has the challenge is to continue the same group members for a long. This is also highlighted by a local government representative. Communities' representative emphasized that their primary roles are to the identification and analyze flood hazards, risks, and vulnerable groups and communicate with actors' representative as well as to conduct the monthly meetings engaged in capacity building training, drill, awareness programs, search and rescue, installing river works, planting trees as a preparedness measure. It shows that the local communities are approaching both vertical and horizontal linkages within a community and to the other village committees' groups. Local said, the NGOs are more concentrating on relief distribution but their appearance is very low in the recovery.

Notwithstanding, in many large-scale flood infrastructure investment pro- 
grams, community-based development activities are often disregarded as elements of project safeguard requirements. In other words, the direct engagement of local communities in project design and implementation is overlooked (youth member, Chhakhapur) added: "due to this the sustainability of large-flood-related infrastructure projects such as dikes or dams or safe shelter houses construction, many times we didn't get basic information about where; shelter houses are going to build, what is the capacity, does that is disabled friendly or not, evacuation route reaches there or not and is their availability of basic facilities or not'.

It is leading towards the project and program unsustainability because of their existing strategies. There is no ownership given to us after the project is finished. "Before and during the implementation of the many projects, NGO groups are not considering our original knowledge and practices on CB-FRM activities, though we are rich in terms of local practices for decades-long" (Project beneficiaries group member, Basanta).

"Most of our communities have two-storey houses made by local resources such as mud, bamboo, and reeds which are very easy to access for aged, pregnant women, disabled people, and Childers to evacuate during the flooding. But we need support to strengthen those houses (e.g., finance and resource)" (Vulnerable group, Sidharwo).

(Flood experiences member, Rajapur), even community-self are frequently doing communication and coordination with upstream communities' people for their activities related to CB-FRM, such as improving agricultural practices, soil erosion control measures, planting, a small dam and culvert construction, river training work, EW message dissemination practices and they do share. Merely, "Community people need some support from NGOs and local governments to develop more strangeness for resilience as well as sustainable activities because downstream communities need to know upstream activities for effective CB-FRM. Yet too high-level engagement has not been done so for. They need a local government presence with more alternative programs".

In some cases, participants felt that due to less involvement in project inception by the community people, the projects deviate from their original responsibility, which directly impacts the local community.

" $A$ year back, there was one project related to construction works [...], a contractor hired outsider laborers to complete the project, where we were ready to work as a volunteer, but the [contractor] denied that. Later, we saw that the contractor used substandard materials to complete the project for a huge profit. The structure was not stable and collapsed within a year. But we could not do anything because the project ws opaque" (Youth Member, Muriya).

As a community, they are doing CB-FRM related work related since long. For that they have formed youth clubs where educated peoples, teachers, and some are known as social activists. Nonetheless, their areas are highly vulnerable to flood-related hazards and they have been losing lives, properties each year except for some year gap of the flooding. Also, they have low literacy and most of them are dependent on agricultural works. During the paddy cultivating and harvest- 
ing time monsoon begins (i.e., June to September or mid-September, but sometimes it appears early or late) which affects their cultivation process (Flood experienced member, Sidharwo). Further, local participants highlighted that the local governance system is significantly important for proactive CB-FRM in addressing our LK and practices on how to address local problems with a better sense of involvement and ownership of theirs. Therewithal, people in the communities are expected to be actively engaged in the process of identification, analysis, monitoring, and evaluation of flood risk to reduce their local vulnerabilities and enhance their capacity towards resilience.

In focus group discussion (FGDs), participants revealed that people in the village engaged in community disaster management funds, where they collect 25 NPR per month from each HHs. If they don't have money, they do collect rice and other ingredients and this process has run every month since 2015. Most of the members are females. The collected amounts they distribute to needy people during the emergency and to recovery aftermath of the disasters, and even they provide loans without interest. Moreover, if any community member gets damaged houses, they build the house with collective support without taking an amount.

The literature emphasized that in the process of recovery, there are always questions that were raised about duplication, and the same point is also seen in the findings from the study. A vulnerable group of male participants, paraykpur), said about duplication activities "in the community during the recovery phases. It is due to the power game and politics. I am a single woman and I have three kids. In the 2017 flood my house destroyed and lost livestock as well, however, I only got 5500 thousand cash in two phases but the ward and local government didn't look at my loss record, even need tarpaulins, blankets, and survival foods, but they distribute to other powerful people because they are active in politics and they get double facilities without losing houses. Despite this, my nearby community youths and women groups helped me back to normal conditions".

Regarding the CB-EWS, ( 2 FGDs, members), emphasized that their community is getting information on water level warning. They are receiving those messages on their cell-phone which helps them to get aware, even each community has a siren that can be aired high pitch sound around two kilometers. Similarly, they have a megaphone or mike. Both devices can be used at the same time to alarm and to keep people prepared to avoid the possible effect of floods. Also, emergency message broadcasts from the local FM/radio to increase more awareness of flood focusing achieved.

On the contrary, others (3-FGDs group members) have a different opinion on this regard, though they agreed with the above FGDs group highlighted points. Despite that, these groups have difficulties understanding the language as most of these groups' village members is speak Tharu and Sonaha language but information received in Nepali are barriers to the effectiveness of communication, and hard to get accurate information at the time of flood for immediate action. 
Nevertheless, all community members are agreed on CB-EWS is effective and meaningful for them as a preparedness measure. Yet, both groups have the same difficulties regard to CB-EWS i.e., information comes late which because of the message dissemination process flow from (Chisapani station-Rajapur station-Local administration office-Municipality office/local police office and then only it reaches up to Local communities/villages), which takes a long time. Thus, the community requested that messages should disseminate on time with a multi-language approach that makes it easy to avoid such barriers and ready to prepared and take proactive action. To incorporate those issues (Flood experienced member, Rajapur) said if NGOs and local governments can coordination with WDMC and CDMC, where the messages can send directly into their system. Later, we have local practices that are chowkidar (Messenger). He can disseminate messages very soon with the available resources i.e., Siren and Mick. Therefore, such practices can help to address the local knowledge as well as practices to builds strong relationships between actors and local peoples, which ultimately establishes proactive CB-FRM.

While acknowledging the essential role that actors play in the CB-FRM, the study has further explored their involvement level based on the three dimensions of SCT. We mainly identified that the level of presence in three categories namely; Low, Medium, and High by following the capitals: bonding (ties within the community members), bridging (ties between the two communities/members), and linking (ties between the government's representative/NGOs-actors with local people) exclusively on preparedness and recovery phases which are summarized in Table 3.

The qualitative information revealed that the community has rarely got a chance to coordinate and collaborate with the actor's which is prominent problems (e.g., people of the community have low participation in the project design-making, selection of areas, ownership distribution, etc.), which showed that linking capital is presence low between actors and local people. Besides this, NGOs do not directly respond to local people's needs basically in the recovery phase, though their presence is quite good in the preparedness activities. Nonetheless, social capitals are continuous build relationship between staff and members which will, therefore, make the transfer of knowledge from the actors to the community easier which states that community's awareness will strengthen knowledge and information, include improved education and training aimed at those who may be exposed more from a disaster. These essential elements seemed low in the community. Meanwhile, actors are underutilization and overlook the LK and practices as well as lacking to utilize low-cost local resources.

The participants explained that the SCT is often utilized in terms of building social networks, assisting each other to rebuild the houses, relocating livestock to relatives and friends neighboring community, borrowing money within a community and outside the community, helping each other during recovery, seeking 
shelter with relative or fellow community member during the initial phase of recovery, sharing LK and practices, information sharing, dissemination of early messages, coordination and communication within the people of the community.

Rajapur flood, an experienced member stated that "The most important about social capital in our community is trust, people interest in their neighborhood has significantly increased, somehow it is due to the disaster activities, and we are feeling our connection is high. Likewise, we often have a meeting with saving group members. In some cases, we ask for a loan within a community and outside the community". It showed that the community has strong bonding, bridging, and linking capitals established.

Furthermore, the community has similar demographic characteristics, ethnic, occupational backgrounds, same socioeconomic status, which is linked with morality, altruism, and humanity. He clearly said that "our capital in humanitarian and human aids, many of the problems and obstacles in an emergency condition are most solved and build community solidarity" (Youth Member, Chhakhapur). Lastly, participants highlighted that the community has a strong relationship with each other while preparing flood management activities and sharing information related to IK (e.g., aged people transfer the LK to the young generation as well as from one to next to the community). Also, the community develops a sense of belongingness, respects their culture while the recovery phase. Overall, within a community and outside the community the three-dimension of social capital is presently high in both phases. However, between the actors and local people bonding, bridging, and linking capital are present median in the preparedness phase but low in the recovery phase.

Table 3. Overall result of social capital in CB-FRM.

\begin{tabular}{|c|c|c|c|c|c|}
\hline \multirow{2}{*}{ Phases } & \multirow{2}{*}{$\begin{array}{c}\text { Social } \\
\text { Capitals }\end{array}$} & \multicolumn{3}{|c|}{ The level of actor's presence in disasters } & \multirow{2}{*}{ Results } \\
\hline & & NGOs & Local Government & Local Community & \\
\hline \multirow{3}{*}{ Preparedness } & Bonding & Medium & Medium & High & Medium \\
\hline & Bridging & Medium & Medium & High & Medium \\
\hline & Linking & Low & Low & High & Low \\
\hline \multirow{3}{*}{ Recovery } & Bonding & Low & Low & High & Low \\
\hline & Bridging & Low & Low & High & Low \\
\hline & Linking & Low & Low & High & Low \\
\hline
\end{tabular}

\subsection{Local Knowledge and Practices in CB-FRM}

While analyzing the participants' interviews, it is shown that the communities' people are applying their LK and Practices. For this study, we prefer to use the terms LK to distinguish from "indigenous knowledge, traditional knowledge, traditional ecological knowledge, rural people's knowledge”, primarily because 
we recognize from the study site. LK is "the people who live in a particular place have about their area" (Laursen, 2015). It is "the knowledge that has evolved within (inside) a specific community or area" (Hiwasaki, Luna, Syamsidik, \& Shaw, 2014). Therefore, in the study, it explored how communities are applying their LK and practicing effectively on CB-FRM. Thus, below we sincerely find it.

\section{Local Knowledge and Practices in Preparedness}

According to (Lewis, 2012) local knowledge is very important in planning for community development. Also, it has been reviving a lot of attention since the 1990s in the field of disaster management (Hiwasaki, Luna, Syamsidik, \& Shaw, 2014). Such LK can reduce the high number of impacts through preparedness measures (e.g., structural or non-structural measures) (Gaillard \& Mercer, 2013). Besides, its potential for improving DRR policies has been discussed on various global platforms, such as the management of disaster in the Asia-Pacific region, regarding the Sendai Framework for action (2015-2030) (Smith, 2011). Also, in the literature, LK and practices play a pivotal role in empowering the local community to take a front role in DRR (Nyong, Adesina, \& Osman Elasha, 2007).

The participants also emphasized that the role of the local community is key in DRR. They are living there for a long. It is due to their local coping and adaptation mechanism. It has indicated that their LK is highly present in the CB-FRM cycle, as an area of their living is very high in terms of flood-hazards. More so, the empirical findings of the study show that LK and practices are used in the preparedness phase of floods, which seems more common than other phases of flood management. As a preparedness measure, LK incorporates several indicators that are already defined by (Portes, 2000) but contextualizing it into this study and presented in Table 4 based on case study findings, and those indicators are; metrological, riverine, phenomenological, ecological and celestial.

During the field observation communities, people indicate that they had already developed their resistant capacity to live in those areas, though they frequently getting floods. The aged community member mentioned that:

"Since my birth (age around 76), I live here and I have seen slowly, the communities getting digesting flood problems; I am suggesting to the new generation to learn our old version of $L K$ and practices how we can survive in our locality with difficulties, though I don't know CB-EWS. I can easily predict when monsoon start and end and even, I can say when heavy rain will happen by looking environment".

For instance, people in the community assume that rainfall models can be estimated clearly by looking at the color and the shape of the clouds. (Flood experienced member, Rajapur) agreed that, the dark clouds crack easily, weak to bring heavy rains, the direction from where the clouds appear looked to have relevance in the local communities of rainfall patterns. Besides, he said that, if clouds appearing in the southern corner of the sky never bring rain but if clouds appearing in the northwest corner of the sky are supposed to bring assured rain 
(metrological indictor).

We also saw that, while visiting vulnerable communities' areas, they were applying IK and skills to build "two-storey" houses by using local resources such as mud, woods, bamboos, reeds, and bushes, which are easily available in the community. The house has shown in Figure 6. They consider those houses are as an emergency shelter (vulnerable community member, "Sonaha"). She highlighted that those houses were practicing since her grandfather's period (in the community more than $80 \%$ HHs have such houses). Still, they are continuously rebuilding that, which is easy to access for an aged group, children's, disable peoples without having difficulties. Except for monsoon season they used those houses to keeping agricultural products. Moreover, local activities such as making "Bakari" (drum) store paddy, wheat, and other food items are the local preparedness measure. Further, the interesting thing is that communities are keeping some other sessional foods such as maize, pumpkin, ginger, garlic, etc. by hanging in the trees. Yet, IK and local practices were overlooked by actors.

As the literature states, LK is a tool that can be used to cope with disasters (Dube \& Munsaka, 2018). Transfer of LK, increasing self-reliance, and sharing the information plays a crucial role in preparedness, response, and recovery phases. In this sense, the actors' groups were provided training that was primarily focused on coping and adaptation strategies, especially choosing the right crops before and after the monsoon. (Flood experienced member, Rajapuruwo). We shared with them our local practices of how we are doing these activities. For instance, the community is preparing agriculture cultivation in both upland and lowland by looking at the season. We change the paddy variety, which is more resistant to water, and agricultural seeds can grow in dryland.

Also, the participants stated that the diverse ethnic groups of people are living in the area such as fishermen and "Sonaha" (gold extraction group) for the river water level need to observe continues. For this, a long bamboo pole is pushed into the riverbed. The person who has near the river bank is a response to note the level (mark) to understand the level of water increase or decrease.

Across the study areas, many key ecological and phenomenological indicators were reported as a preparedness measure based on LK. Apparently, precise moves of ants and loud sounds from frogs meant either heavy rain or floods. Also, the display of small red ants moving around the houses with their white color eggs in their head symbolizes appearing flood. Perhaps, there is an appearance of black ants before the start of heavy rains. It incites coming out from inside the land with large numbers and carrying their white color eggs in head or mouth and move with a decent line or making a track or if they do not move in a decent track, then it is symbolic of some other trouble. If they do, then it indicates either heavy rains or a flood (Old-age member, Muriya).

Despite having rich in the LK, actors and local governments are still overlooked. However, it needs to be incorporating those important and essential capacities of local people, which ultimately help towards resilience. (Youth member, Rajapur) said, we know that technology is more applicable rather than local 
practices but we also know that technology presence in DRR recently, where $L K$ and its practices present for very long to minimize the hazards. But with a combination of LK and new advanced technology can create more resilience of the community people.

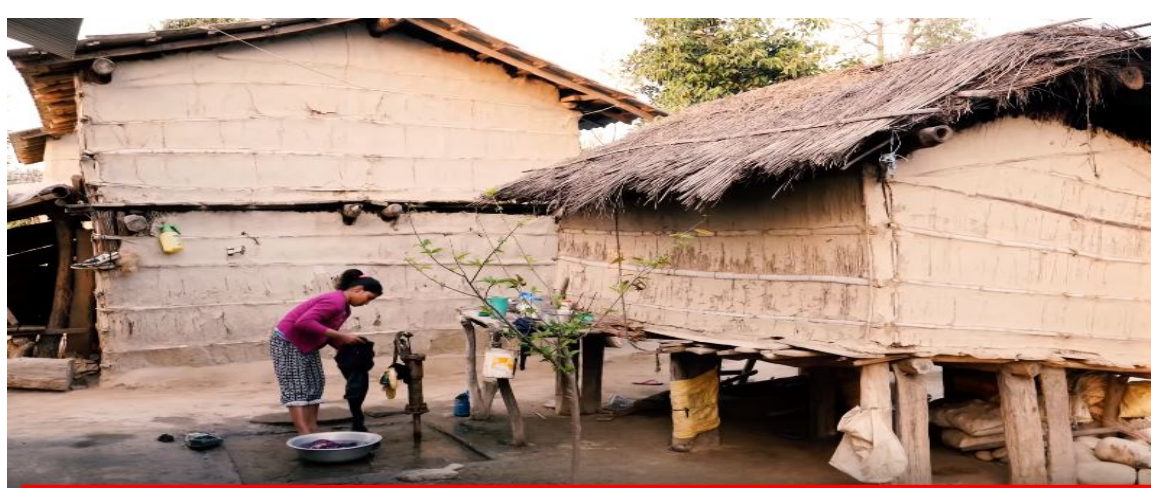

Figure 6. Two-storey house built by community peoples for emergency shelter (as a Preparedness measure).

\section{Local Knowledge and Practices in Recovery}

LK and its practices are applicable in the recovery phase as well but as compare to preparedness it seems relatively low. Participants stated that is mainly because they have been themselves affected, and cannot often help others. Albeit, they distribute collected money which they were collected in the pre-disaster phase.

"We have a total of 2.5 lakh rupees in our community disaster management fund that has been collected since its inception, in which we provide cash to back the normal condition. However, we provide that money basis of need, sometimes we provide money without interest and sometimes we distribute relief items for quick recovery such as fast foods, tarpaulins, blankets, and medicine. But, we can able to assist community members in the initial phase only. Later we need more support which we are getting from the local government and NGOs, though there are challenges regard to duplication (Flood experienced member, Chhakhapur).

Furthermore, the study found that the communities build a temporary shelter during the quick recovery. In some cases, when flood damage river bridge. They build to assist those who need to cross the village and children going to school. The literature also stated that LK and practice add value to the recovery phase and can be a useful input in a communities' endeavor to face challenges posed by disasters. After the flooding's LK and practice strategies that are primarily applicable to rebuild damaged houses, psychological assistant, restore livelihoods, and other aid support. (Vulnerable member, Tigra) explained that if a community member's house gets damaged, they support rebuilding the house in the same place but if there is available space, they leave the old place. Furthermore, sometimes rebuilding a house in a different location requires new land which is problematic for people already living in poverty. Commonly, houses are rebuilt in the 
same manner with marginal improvement (e.g., strengthening the wall). Also, they reported that they might change the method of construction if they have money; if they do not enough money, they just build houses with bricks and mud.

Table 4. Overview of different LK practices and their indicators at the research site.

\begin{tabular}{|c|c|c|}
\hline Indictors & Explanation of indicators & Result of Possibility \\
\hline Metrological & $\begin{array}{l}\text { - } \quad \text { Heavy wind movement } \\
\text { - } \quad \text { Color and shape of clouds (Dark clouds) } \\
\text { - } \quad \text { Rain patterns } \\
\text { - } \quad \text { Clouds appearing in the northwest corner of the sky } \\
\text { - } \quad \text { Clouds appearing in the southern corner of the sky } \\
\text { - } \quad \text { Hot temperatures }\end{array}$ & $\begin{array}{ll}\text { - } & \text { Heavy rain (for a short duration) } \\
\text { - } & \text { Weak to bring heavy rains } \\
\text { - } & \text { Assuming for the length of rainy days } \\
\text { - } & \text { Assuming rain } \\
\text { - } & \text { Never bring rain } \\
\text { - } & \text { Assuming rain after a few days }\end{array}$ \\
\hline Riverine & $\begin{array}{l}\text { - Watercolor change (dark/gray/muddy) upstream to downstream } \\
\text { - } \quad \text { Rate of water level increase } \\
\text { - } \quad \text { Water sound } \\
\text { - } \quad \text { Fish is not visible in the river }\end{array}$ & $\begin{array}{ll}\text { - } & \text { Assuming flood (heavy rain upstream) } \\
\text { - } & \text { Flood happen very shortly } \\
\text { - } & \text { River water increase (Flood events) } \\
\text { - } & \text { Heavy rain upstream (Flood events) }\end{array}$ \\
\hline Phenomenological & $\begin{array}{l}\text { - A noise comes from a habitation } \\
\text { - } \quad \text { Continuously increasing temperature } \\
\text { - } \quad \text { An elderly member of the house feeling pain (certain body part) } \\
\text { - } \quad \text { Kids make a different sound (sound created from lips- "fur-fur-fur") }\end{array}$ & $\begin{array}{ll}\text { - } & \text { Flood Event (Nearby in the community) } \\
\text { - } & \text { Heavy rain shortly } \\
\text { - } & \text { Assuming rain } \\
\text { - } & \text { High chance of rain }\end{array}$ \\
\hline Ecological & $\begin{array}{l}\text { - } \quad \text { Frog producing a loud sound } \\
\text { - Animal behaviors change (migrating from the river to the land) } \\
\text { (e.g., crocodile) } \\
\text { - Display red ants moving around the house with white eggs in } \\
\text { their head } \\
\text { - } \quad \text { Appearing black color-ants and moving straight line } \\
\text { - Appearing all of a sudden snake in the community } \\
\text { - Bamboo plant growing next to the river banks }\end{array}$ & $\begin{array}{ll}\text { - } & \text { Approaching heavy rain } \\
\text { (continue for few days) } \\
\text { - } \quad \text { High chance of rain (flood) } \\
\text { - } \quad \text { Symbolize appearing flood soon } \\
\text { - } \quad \text { Weak to bring heavy rains } \\
\text { - } \quad \text { Approaching heavy rain very shortly } \\
\text { - } \quad \text { Monsson season started }\end{array}$ \\
\hline Celestial & $\begin{array}{l}\text { - The appearance of the specific constellation in the sky } \\
\text { - } \quad \text { Full moon } \\
\text { - } \quad \text { Appearing of Orion star }\end{array}$ & $\begin{array}{ll}\text { - } & \text { Rain shortly } \\
\text { - } & \text { Assuming rain } \\
\text { - } & \text { Assuming rain }\end{array}$ \\
\hline
\end{tabular}

\section{Conclusion}

The research presented here aimed to explore the CB-FRM context through the involvement of actors by practicing LK on preparedness and recovery phases in the Lower Karnali River Basin (a case study of Rajapur, Bardiya). The study areas are considered highly-flood pone. Findings were critically examined according to the major theme. The study has drawn several conclusions. The non-government organizations and local governments are playing a pivotal role in establishing the concept of CB-FRM; however, their working approaches may also need to change from top-down to bottom-up (people-centric/participatory). Further, their involvement needs to be more focused on both vertical and horizontal to the effective connection between actors' and the local communities. Also, it seems from the result that their program implementation is oriented towards relief assistance; this aligns with the findings of (Dube \& Munsaka, 2018), although preparedness and recovery remain prominent and a large investment gap in CB-FRM is evident. The study likewise originates that LK and their prac- 
tices play an important part in CB-FRM activities, which are also highlighted by (Shaw, 2012a). Those LK cuts across different phases of the CB-FRM cycle, which indicated that the local community has diverse knowledge and practicing systems that possess a creative set of strategies based on the LK and that allows them to live in the flood-prone areas, accepting the paradigm shift from "fighting with floods" to "living with floods" as novel "way of life". But yet actors often neglect and underutilization the LK and practices. The study further highlighted that DRR practitioners can integrate modern technology with IK and practices so that DRR interventions become more effective.

Furthermore, the result revealed that the existing top-down system in Nepal requires improvement, particularly in the sense of coordination, communication, participation, transparency, accountability, and distribution of roles and responsibilities for line government bodies towards proactive action. These problems have been seen in most of the developing countries, such as India, Vietnam, and Bangladesh (Trogrlić et al., 2019). To address that, (Shaw, 2012a) highlighted if CB-FRM activities work progressive action-participation approach through the concept of "practice to the policy", it leads towards resilience, which is also emphasized in the current study. Although GoN has a six-layer of government system from the central to the local level, there is no standard communication protocol with NGOs defined yet and this is leading towards duplication in different phases of the DRRM cycle. In line with this, research in Malawi (Trogrlić et al., 2019) has the same problems raised.

More so, findings revealed a wide range of challenges regarding project sustainability, exit strategies, and ownership in the process of CB-FRM by NGOs. This is highlighted by each FGDs member which reflects that the social capital is weak between the actors and local people except for within the community people. However, the local government has a very low number of programs in the community related to flood management. They are dependent on NGOs' projects which is not enough for the community. Despite that, actors were not considered LK in their projects which is a prominent issue in other respective countries as well.

Furthermore, the findings revealed that LK is easily approachable than technical (e.g., local recovery methods, using local resources mud, bamboo, reeds, grass to rebuild houses if damaged due to floods), and includes social dynamics traits which meant informal communication patterns, knowledge transfer, idea sharing, easy conversation with upstream community people. One more feature relating to the social dynamics of LK is its locally bound characters, which helps them to participate in local activities in mass during preparedness and recovery phases. Similarly, they have been helping each other by providing shelter to rebuild new houses. Though the result indicates that LK differs from one community to another community, however, the patterns are similar (e.g., celestial and ecological assumption on preparedness measures are the same).

Moreover, the social capitals result indicated that the social-dimension plays a crucial role in effective CB-FRM actions. In the study areas, it is present in all the 
phases of CB-FRM. Though, their level of presence has a difference. Where participants explained that social networks are often utilized. Based on literature evidence, bonding capital is more essential in preparedness. However, this research has revealed additional arguments for looking at social capital critically. The facts that community's people utilized all three social capitals (i.e., bonding, bridging, and linking) equally on the preparedness and recovery phases; especially within communities' people. The community in the sense of sharing LK, practices, network creation, information sharing, social cohesion, participation in preparedness activities, risk awareness, training participations, identifies the hazards. But community with NGOs and government bodies linking capital has a relatively low level of presence as compared with bonding and bridging. It is identified that NGOs have overlooked local people's engagement in the process of project implementation and even in the selection of areas. In recovery, there is directly influenced by the government itself.

The investigation has shown that the CB-FRM practices in Nepal and other developing nations (e.g., Bangladesh, Vietnam, and Malawi) have the same gaps (i.e., top-down approach which is weak to address communities' problems effectively). Thus, community people have changed their way of living and strategy by welcoming "living with the flood as a way of life" and "watch and act" with practicing LK on this statement where (Trogrlić et al., 2019) also agreed. On the other hand, developed nations (e.g., Japan and England) have practiced CB-FRM which is well established. They have been operating CB-FRM on bottom-up and people-centric approaches rather than the top-down approach. Also, they introduced voluntary notions (e.g., the community can share their LK and practices) which is helping to address the local issues directly. Therefore, it indicates that the development and improvement of FRM are required to change in developing nations through the understanding of local challenges, their adopting capacities, and incorporating LK. Even these highlighted points were repeatedly noticed in this study.

For instance, in the study areas participants stated that EW message receives in the phone and they know it is well but that is not practically feasible as always for them-From the Chisapani station emergency alert messages are broadcast about to prepare but at that time in the community there are no raining at all, even by look the messages we didn't trust and later also nothing went wrong. In this regard, if incorporate LK practices in the preparedness phase (e.g., looking at sky colors can assume that rains will happen or not), though is not a $100 \%$ guarantee and the same to the technical system as well. In the future, the trust will decrease toward EWS if the problems have not adequately address. Since participants often highlighted during the FGDs. It shows that the combined efforts (i.e., technology and LK) are the best for effective CB-FRM and CB-DRR which was (Portes, 2000) also emphasized.

In general, it was noticed that the communities lack to understand modern technology. On the other side, DRR practitioners lack to address IK and practices. If they both consider these points as a result, immensely benefit will get while 
dealing with disaster events at any time. Actors' involvement and LK practices in CB-FRM especially on preparedness and recovery phases need to take full consideration based on the local realities. The research reported herein indicates that LK practices are multi-purposed which must need to be continuing with its real benefits for CB-FRM. Also, this means a strong message that existing approaches need to be a rethink and redesign in a manner that will build a platform for actors' involvement process in the right way with consideration of several aspects of community engagement towards resilience. Actors' involvement at the community level is always beneficial for the community people to enhance their capacities. However, several challenges can be minimized if the community-participation approach comes into priorities from each actor and also can reduce the duplications if the local government designs the proactive communication protocol for NGOs and other respective actors. Besides, social capitals play a very crucial role to work together which is also enlightened in the study. The gaps can reduce especially between the actors and the local community. This further makes a valuable understanding of the dynamic process of CB-FRM and CB-DRR, which provides a valuable addition to the literature. The study especially shows that NGOs and local governments that are involved in CB-FRM in Nepal need to be changed as a holistic approach to CB-FRM and to create a more balanced strategy between top-down and bottom-up approaches. Thus, this research provides evidence from the ground-up that can faster be thinking among the other CB-FRM actors in Nepal. Nevertheless, if we develop a degree of self-help and self-organization that is best achieved through CB-FRM. Hence, the actors' involvement and utilization of LK practices can serve as a blueprint for those who are involving in community-based related work and especially in CB-FRM. Likewise, it helps academicians, practitioners, and concerned stakeholders.

With the number of limitations such as data collection, involved in two phases' preparedness and recovery. However, significant efforts were carried out to reduce such an error throughout the study. Due to limitation, the study has shown few managerial implications. Firstly, the actors need to change their mode of preparedness and recovery by addressing LK and practices. Secondly, community-based approaches have been motivated people to work together because they feel a sense of belongingness as well as the dynamic process that allows them to contribute to comprehensive decision-making processes and problem-solving. Lastly, the study indicates that the potential value of social capital in disaster planning is a great opportunity for the establishment of CB-FRM.

\section{Limitation of the Study}

This section looks at the limitation of the overall study. The limitation of this study was primarily apprehensive about the section of data collection. Also, the study has only investigated especially in two phases' preparedness and recovery. The study is mainly concerned with a case study and the area covered is limited. Significant efforts were carried out to reduce the error while transcribing and 
translating of FGDs and KIIs. Nevertheless, due to time limits, the real-time translation was not conducted. It might be creating an error. The cultural factors may also have influenced the information shared basically in FGDs. Lastly, due to the financial and logistical constraints, many respective representatives have limited such as academia and national level DRR experts.

\section{Conflicts of Interest}

The author declares no conflicts of interest regarding the publication of this paper.

\section{References}

Adhikari, B. R., \& Sitoula, N. R. (2018). Community Based Flash Flood Early Warning System: A Low-Cost Technology for Nepalese Mountains. Bulletin of the Department of Geology, 20, 87-92. https://doi.org/10.3126/bdg.v20i0.20728

Ahmad, A., \& Zahir Ahmed, M. (2019). Law Can Set a Stage for Disaster Risk Reduction: A Study on Nepal. In B. Zutshi, A. Ahmad, \& A. B. Srungarapati (Eds.), Disaster Risk Reduction: Community Resilience and Responses (pp. 3-17). Singapore: Palgrave Macmillan. https://doi.org/10.1007/978-981-10-8845-2_1

Allen, K. M. (2006). Community-Based Disaster Preparedness and Climate Adaptation: Local Capacity-Building in the Philippines. Disasters, 30, 81-101. https://doi.org/10.1111/j.1467-9523.2006.00308.x

Atta-ur-Rahman, \& Khan, A. N. (2011). Analysis of Flood Causes and Associated Socio-Economic Damages in the Hindukush Region. Natural Hazards, 59, Article No. 1239. https://doi.org/10.1007/s11069-011-9830-8

Bajracharya, S. R., Shrestha, M. S., \& Shrestha, A. B. (2017). Assessment of High-Resolution Satellite Rainfall Estimation Products in a Streamflow Model for Flood Prediction in the Bagmati Basin, Nepal. Journal of Flood Risk Management, 10, 5-16. https://doi.org/10.1111/jfr3.12133

Bhattarai, T. N. (2018). Flood Events in Gangapur Village, Banke District: An Example of Climate Change-Induced Disaster in Nepal. Journal of Institute of Science and Technology, 19, 79-85. https://doi.org/10.3126/jist.v19i1.13832

Bosher, L., \& Dainty, A. (2011). Disaster Risk Reduction and "Built-In" Resilience: Towards Overarching Principles for Construction Practice. Disasters, 35, 1-18. https://doi.org/10.1111/j.1467-7717.2010.01189.x

Dube, E., \& Munsaka, E. (2018). The Contribution of Indigenous Knowledge to Disaster Risk Reduction Activities in Zimbabwe: A Big Call to Practitioners. Jàmbá: Journal of Disaster Risk Studies, 10, Article No. a493. https://doi.org/10.4102/jamba.v10i1.493

Gaillard, J. C., \& Mercer, J. (2013). From Knowledge to Action: Bridging Gaps in Disaster Risk Reduction. Progress in Human Geography, 37, 93-114. https://doi.org/10.1177\%2F0309132512446717

Gautam, D. K., \& Phaiju, A. G. (2013). Community Based Approach to Flood Early Warning in West Rapti River Basin of Nepal. IDRiM Journal, 3, 155-169. https://doi.org/10.5595/idrim.2013.0060

Gero, A., Méheux, K., \& Dominey-Howes, D. (2011). Integrating Community Based Disaster Risk Reduction and Climate Change Adaptation: Examples from the Pacific. https://doi.org/10.5194/nhess-11-101-2011 
Hiwasaki, L., Luna, E., Syamsidik, \& Shaw, R. (2014). Process for Integrating Local and Indigenous Knowledge with Science for Hydro-Meteorological Disaster Risk Reduction and Climate Change Adaptation in Coastal and Small Island Communities. International Journal of Disaster Risk Reduction, 10, 15-27. https://doi.org/10.1016/j.ijdrr.2014.07.007

Hollweck, T. (2016). Case Study Research Design and Methods (5th Ed.).

Iloka, N. G. (2016a). Indigenous Knowledge for Disaster Risk Reduction: An African Perspective. Jàmbá: Journal of Disaster Risk Studies, 8, Article No. a272. https://doi.org/10.4102/jamba.v8i1.272

International Federation of Red Cross (IFRC) (2018). World Disasters Report 2018: Leaving No One Behind. Paris: International Federation of Red Cross.

Izumi, T., \& Shaw, R. (2012). Chapter 3 Role of NGOs in Community-Based Disaster Risk Reduction. In R. Shaw (Ed.), Community-Based Disaster Risk Reduction (Vol. 10, pp. 35-54). Bingley: Emerald Group Publishing Limited.

https://doi.org/10.1108/S2040-7262(2012)0000010009

Joerin, J., Shaw, R., Takeuchi, Y., \& Krishnamurthy, R. (2012). Assessing Community Resilience to Climate-Related Disasters in Chennai, India. International Journal of Disaster Risk Reduction, 1, 44-54. https://doi.org/10.1016/j.ijdrr.2012.05.006

Jones, S., Oven, K. J., Manyena, B., \& Aryal, K. (2014). Governance Struggles and Policy Processes in Disaster Risk Reduction: A Case Study from Nepal. Geoforum, 57, 78-90. https://doi.org/10.1016/j.geoforum.2014.07.011

Kanta Kafle, S. (2018). How Resilient Are Our Communities. Continuity, 28-29.

Laursen, M. R. (2015). CBDRM in Nepal: A Matter of Risk Perceptions. International Journal of Disaster Resilience in the Built Environment, 6, 73-85. https://doi.org/10.1108/IJDRBE-07-2014-0052

Lee, A. C. K. (2016). Barriers to Evidence-Based Disaster Management in Nepal: A Qualitative Study. Public Health, 133, 99-106. https://doi.org/10.1016/j.puhe.2016.01.007

Leonard, R., \& Onyx, J. (2004). Social Capital \& Community Building: Spinning Straw into Gold. London: Janus Publishing Company.

Lewis, J. (2012). The Good, The Bad and The Ugly: Disaster Risk Reduction (DRR) Versus Disaster Risk Creation (DRC). PLOS Currents Disasters.

https://doi.org/10.1371/4f8d4eaec6af8

Meyer, M. A. (2018). Social Capital in Disaster Research. In H. Rodríguez, W. Donner, \& J. E. Trainor (Eds.), Handbook of Disaster Research (pp. 263-286). Cham: Springer International Publishing.

Miller, N. (2001). Contributions of Social Capital Theory in Predicting Rural Community in Shopping Behavior. The Journal of Socio-Economics, 475-493.

https://doi.org/10.1016/S1053-5357(01)00122-6

Minamoto, Y. (2010). Social Capital and Livelihood Recovery: Post-Tsunami Sri Lanka as a Case. Disaster Prevention and Management: An International Journal, 19, 548-564. https://doi.org/10.1108/09653561011091887

Ministry of Home Affairs (2019). Nepal Disaster Risk Reduction Portal. http://drrportal.gov.np/

Nakagawa, Y., \& Shaw, R. (2004). Social Capital: A Missing Link to Disaster Recovery. International Journal of Mass Emergencies and Disasters, 22, 5-34.

Nepal, P., Khanal, N. R., \& Pangali Sharma, B. P. (2018). Policies and Institutions for Disaster Risk Management in Nepal: A Review. Geographical Journal of Nepal, 11, 
1-24. https://doi.org/10.3126/gjn.v11i0.19546

NPC Report (2017). Post Flood Recovery Needs Assessment, 2017.

Nyong, A., Adesina, F., \& Osman Elasha, B. (2007). The Value of Indigenous Knowledge in Climate Change Mitigation and Adaptation Strategies in the African Sahel. Mitigation and Adaptation Strategies for Global Change, 12, 787-797. https://doi.org/10.1007/s11027-007-9099-0

Pandey, B., \& Okazaki, K. (2005). Community Based Disaster Management: Empowering Communities to Cope with Disaster Risks. Corpus ID: 18865534.

Pandey, C. L. (2019a). Making Communities Disaster Resilient: Challenges and Prospects for Community Engagement in Nepal. Disaster Prevention and Management: An International Journal, 28, 106-118. https://doi.org/10.1108/DPM-05-2018-0156

Parvin, G. A., Takahashi, F., \& Shaw, R. (2008). Coastal Hazards and Community-Coping Methods in Bangladesh. Journal of Coastal Conservation, 12, 181-193.

https://doi.org/10.1007/s11852-009-0044-0

Portes, A. (2000). The Two Meanings of Social Capital. Sociological Forum, 15, 1-12. https://doi.org/10.1023/A:1007537902813

Poudyal Chhetri, M. B. (2001). A Practitioner's View of Disaster Management in Nepal: Organisation, System, Problems and Prospects. Risk Management, 3, 63-72. https://doi.org/10.1057/palgrave.rm.8240102

Shaw, R. (2006). Critical Issues of Community Based Flood Mitigation: Examples from Bangladesh and Vietnam. Journal of Science \& Culture, 72, 1-17.

Shaw, R. (2012a). Chapter 1 Overview of Community-Based Disaster Risk Reduction. In R. Shaw (Ed.), Community-Based Disaster Risk Reduction (Vol. 10, pp. 3-17). Bingley: Emerald Group Publishing Limited. https://doi.org/10.1108/S2040-7262(2012)0000010007

Shaw, R., \& Krishnamurthy, R. R. (2009). Disaster Management: Global Challenges and Local Solutions. https://doi.org/10.1108/dpm.2010.19.4.518.7

Shiwaku, K., \& Shaw, R. (2008). Proactive Co-Learning: A New Paradigm in Disaster Education. Disaster Prevention and Management: An International Journal, 17, 183-198. https://doi.org/10.1108/09653560810872497

Smith, P. J., Brown, S., \& Dugar, S. (2017). Community-Based Early Warning Systems for Flood Risk Mitigation in Nepal. Natural Hazards and Earth System Sciences, 17, 423-437. https://doi.org/10.5194/nhess-17-423-2017

Smith, T. A. (2011). Local Knowledge in Development (Geography). Geography Compass, 5, 595-609. https://doi.org/10.1111/j.1749-8198.2011.00443.x

Tanwattana, P. (2018). Systematizing Community-Based Disaster Risk Management (CBDRM): Case of Urban Flood-Prone Community in Thailand Upstream Area. International Journal of Disaster Risk Reduction, 28, 798-812.

https://doi.org/10.1016/j.ijdrr.2018.02.010

Trogrlić, R. Š. Wright, G., Adeloye, A., \& Duncan, M. J. (2019). Community Based-Flood Risk Management: Experiences and Challenges in Malawi. https://doi.org/10.3390/su11061681

Tuladhar, G., Yatabe, R., Dahal, R. K., \& Bhandary, N. P. (2015). Disaster Risk Reduction knowledge of Local People in Nepal. Geoenvironmental Disasters, 2, Article No. 5. https://doi.org/10.1186/s40677-014-0011-4

United Nations Development Program, Bureau for Crisis Prevention and Recovery (UNDP/BCPR) (2018). Reducing Disaster Risk: A Challenge for Development. Geneva: United Nations Development Program, Bureau for Crisis Prevention and Recovery. 
United Nations Office for Disaster Risk Reduction (UNDRR) (2019). United Nation Disaster Risk Reduction DesInventar. Geneva.

Wannous, C., \& Velasquez, G. (2017). United Nations Office for Disaster Risk Reduction (UNISDR)-UNISDR's Contribution to Science and Technology for Disaster Risk Reduction and the Role of the International Consortium on Landslides (ICL). In K. Sassa, M. Mikoš, \& Y. Yin (Eds.), Advancing Culture of Living with Landslides (pp. 109-115). Cham: Springer International Publishing. https://doi.org/10.1007/978-3-319-59469-9 6

Yin, R. K. (2014). Case Study Research Design and Methods (5th ed.). Thousand Oaks, CA: Sage. 282 p. 